\title{
Vildagliptin and Insulin Combinatorial Therapy Drug Safety Monitoring in Diabetic Rats
}

\author{
Priya Ebenesan ${ }^{1}$ and Mallika Jainu ${ }^{2}$ \\ ${ }^{1}$ Department of Biochemistry, Research and Development Centre, Bharathiar University, Coimbatore - 641046, Tamil Nadu, INDIA \\ ${ }^{2}$ Department of Biomedical Engineering, Sri SivaSubramaniya Nadar College of Engineering, Kalavakkam, Chennai -603110, INDIA.
}

\begin{abstract}
Background: Type 2 Diabetes Mellitus is a long term metabolic disorder that is characterized by high blood sugar, insulin resistance, and lack of insulin. Based on the understanding of the pathogenesis of T2DM, several distinct pharmacological therapies have been developed but many of them are producing significant adverse drug reactions. Objectives: The present study helps to understand the progression of hepatic degeneration in diabetes mellitus upon treatment with vildalgliptin and insulin. This study is aimed to evaluate the toxicity of combined therapy of vildagliptin and insulin in alloxan induced diabetic rats. Methods: Adult male albino Wistar rats were distributed among 5 groups, and induced diabetes with alloxan. The alterations in glucose metabolizing enzyme activities were determined spectrophotometrically in the liver homogenate and confirmed by histological study. The hematological count has been carried out in all experimental groups to understand the toxicity of combinatorial therapy. Results: The histopathological studies showed pathological changes in the cellular architecture and microcytic hepatic nuclei. The level of haemoglobin, red blood cells and platelet count has been lowered drastically when compared to the monotherapy showing that the combinatorial therapy makes the animal anaemic. The level of lymphocytes has been considerably reduced in the combinatorial therapy showing the loss of immunity. The glucose metabolizing enzymes have been significantly altered showing the glucose metabolism is severely affected in combinatorial therapy showing it was not properly metabolized. Conclusion: The above studies have clearly proves that vildagliptin and insulin drug therapy shows toxicity on metabolic organs and blood cells. So our studies will be really helpful for developing new drugs which are devoid of adverse effects.
\end{abstract}

Key words: Vildagliptin, Insulin, Hepatic tissues, Incretins, Adverse effects.

\section{INTRODUCTION}

The ADR [Adverse Drug Reaction] has been defined by the WHO [World Health Organization] as a response to a drug which is noxious and unintended and it usually occurs at doses normally given for the treatment of a disease or for the modification of a physiological function. ${ }^{1}$ The drugs are passing through various clinical trials but only after they enter the market only the doctors and other health care professionals are also able to monitor them only after that and that is not usually done and also they are unaware of the steps they have to take if a patient is brought to the hospital due to adverse drug reaction. Diabetes has been a mass killer on globe for quite a long time now. There have been several previous estimates of the number of persons with diabetes. ${ }^{2}$ The drugs given for the Type 2 Diabetes Mellitus may produce a number of side effects like tremors, ulceration of the foot and dizziness. The challenge of treating diabetes in this section of population is to avoid hypoglycemia. The elderly are frequently on polypharmacy, which opens the door for potential drug interactions. ${ }^{3}$ Type 2 diabetes is a multifaceted pathophysiological disorder which
Submission Date: 19-09-2016; Revision Date: 17-11-2016; Accepted Date: 20-11-2016

DOI: 10.5530/ijper.51.1.20 Correspondence: Dr. Mallika Jainu, Assistant professor, Department of Biomedical Engineering, SSN College of Engineering, OMR Road, Kalavakkam Chennai-603110,

Tamil Nadu, INDIA.

Mobile: 9444788132

Email: mallikajain@gmail.com

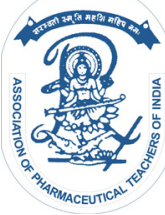

www.ijper.org 
includes insulin resistance, impaired glucose tolerance, impaired islet function and high hepatic glucose production during fasting conditions. The insulin resistance remains the same over time and the islet function deficit is a progressive phenomenon producing abnormalities in the secretion of insulin and glucagon which is accompanied by the decrease in the ability to secrete required quantity of insulin. The defect in the islet function may get worsened with the history of the disease. ${ }^{4}$ The management of Type 2 Diabetes is proper exercise and taking balanced diet and increase in the other physical activities to increase glucose utilization and to promote weight loss. This should be accompanied by the treatment with the oral antidiabetic agents and if required insulin injections can also be taken along with it. Many newer therapies have come to the market recently in order to increase the secretion of insulin and also in order to counteract the negative effects of being used with metformin. One such novel therapy that has come to the market recently is the Dipeptidyl Peptidase IV [DPP-4] group of inhibitors which will instantaneously inactivate the two incretin hormones that are secreted in response to the passage of food through the gut which are Glucagon like peptide-1 [GLP-1] and Glucose dependent Insulinotropic Peptide [GIP]. ${ }^{5}$ By creating a natural balance in the level of the above said incretin hormones it helps in the effective response of the alpha and beta cells of the pancreatic tissue to the level of glucose in the blood thereby balancing the level of insulin and glucagon secretion in the body. DPP4 inhibitors are the first oral agents to treat both alpha and beta cell dysfunction which exists in Type 2 Diabetes Mellitus. ${ }^{6}$ This article provides an overview of the combined antidiabetic effects of the DPP4 inhibitor vildagliptin and insulin on the liver tissues, level of glucose metabolising enzymes and the haematological parameters.

\section{MATERIALS AND METHODS}

\section{Experimental animals}

Adult male Wistar Albino rats weighing 150-200g were used for the present investigation. They were housed in a clean polypropylene cage and maintained under standard laboratory conditions (temperature $25 \pm 2^{\circ} \mathrm{C}$ with dark/light cycle 12/12h). They were fed with standard pellet diet (Hindustan lever, Kolkata, India) and water . The animals were acclimatized to laboratory conditions for one month to experiment. All procedures described were reviewed and approved by the animal ethics committee (IAEC No/03/006/2014).

\section{Induction of diabetes}

Freshly prepared solution of alloxan was given to rats in fasting for 18 hours in dosage of $150 \mathrm{mg} / \mathrm{kg}$ i. p thereby they were induced for diabetes. 48hours after injection, the rats with blood glucose level above $250 \mathrm{mg} / \mathrm{dl}$, were considered hyperglycemic and they were used for the study.

\section{Experimental design}

The animals were divided into 5 groups consisting of 6 animals in each group.

Group I : Rats received normal saline ( $1 \mathrm{ml} / \mathrm{kg}$ b.wt), Group II: Rats administered with alloxan (150mg/ $\mathrm{kg} /$ day) is injected intraperitoneally as a single dose to induce diabetes. ${ }^{7}$

Group III: Diabetic rats treated with vildagliptin $(0.69 \mathrm{mg} / \mathrm{kg}$ b.wt $)$ given orally as a single dose for 10 days. ${ }^{8}$

Group IV: Diabetic rats treated with insulin (0.27 IU/ $\mathrm{kg}$ b. wt) administered i. m. as a single dose for 10 days. ${ }^{9}$ Group V: Diabetic rats treated with same dose of insulin (0.27 IU $/ \mathrm{kg}$ b.wt) i.m and vildagliptin $(0.69 \mathrm{mg} / \mathrm{kg}$ b. wt) orally for 10 days.

After monitoring, animals were sacrificed by injecting with sodium pentabarbitone and blood was collected in plain and heparinized tubes immediately after sacrifice for biochemical assays. Blood samples centrifuged for $10 \mathrm{~min}$ at $2500 \mathrm{rpm}$ and the serum separated stored at $4^{\circ} \mathrm{C}$ until further investigations.

\section{Histological examination}

The hepatic tissue were excised from the animals and were immersed in 10\% formalin solution and after formal processing, they were embedded in paraffin wax and thin sections of $5 \mu \mathrm{m}$ thickness were cut down and stained using hematoxylin and eosin for microscopic examinations.

The glucose metabolizing enzymes such as hexokinase, pyruvate kinase, glucose-6-phosphatase, glucose6-phosphate dehydrogenase was determined using standard Span diagnostic kits measuring in Shimadzu UV-Visible spectrophotometer. The haematological parameters such as RBC, haemoglobin, PCV, platelet count have been measured by Neubaer counting chamber, Drabkin's reagent, Wintrobe tube, Counting chambers respectively.

\section{Statistical analysis}

Results will be expressed as mean \pm S. E. M. Statistical significance is determined by one-way analysis of variance (ANOVA) and dunnet's post hoc test. $\mathrm{P}$ values less than 0.05 will be considered significant. For data 
processing SPSS data analysis software version 21.0 was used.

\section{RESULTS}

\section{Combined therapy drug toxicity on hepatic morphology}

Control animal liver section showing normal hepatic architecture, hepatocytes, portal triad and central vein (Figure 1A). Sections from the animals treated with alloxan are showing hepatic lesions and large size of neutrophil infiltration (Figure 1B). Sections from the animals treated with alloxan and insulin are showing reduced size of neutrophil infiltration (Figure 1C). Sections from the animals treated with alloxan and vildalgliptin shows the recovery of normal hepatocytes (Figure 1D). Sections from the animals treated with and alloxan and vildalgliptin + insulin shows microcytic hepatic nuclei, pathological changes in the cellular architecture (Figure 1E).

\section{Effect of insulin and vildalgliptin on haematological parameters}

The level of neutrophils have been elevated due to enhanced infections in the combinatorial therapy
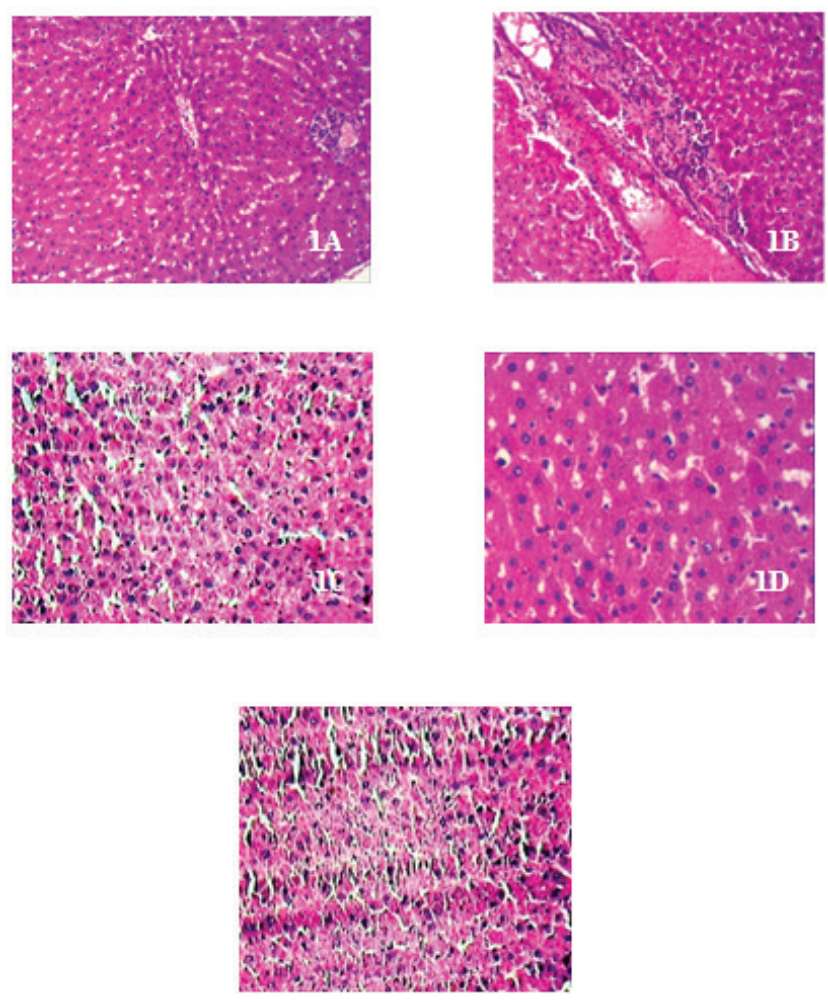

Figure 1: Effect of vildagliptin and insulin on hepatic tissues morphology in alloxan-treated rats, the damage was evident from the $\mathrm{H}$ E stained tissue section under 200x magnifications. 1A - Normal control; 1B- alloxan induced; 1C- alloxan + vildlagliptin treated; 1D - alloxan + insulin treated; $1 \mathrm{E}$-alloxan + insulin + vildalgliptin treated.

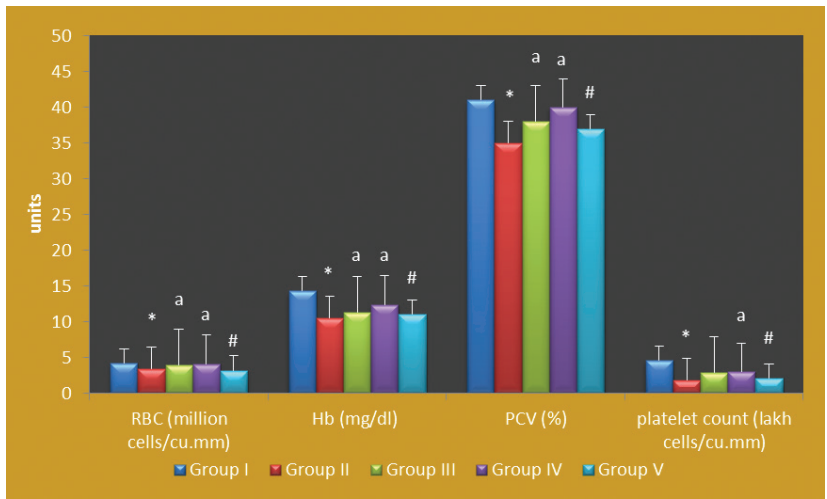

Figure 2. Effect of vildagliptin and insulin on white blood cells in diabetic rats. Results are expressed as mean \pm S.E.M, $n=6$. ${ }^{*} P<0.001$, statistically significant as compared with control rats: aP< 0.01 , statistically significant as compared with diabetic rats and $\# \mathrm{P}<0.01$, statistically significant as compared with normal.

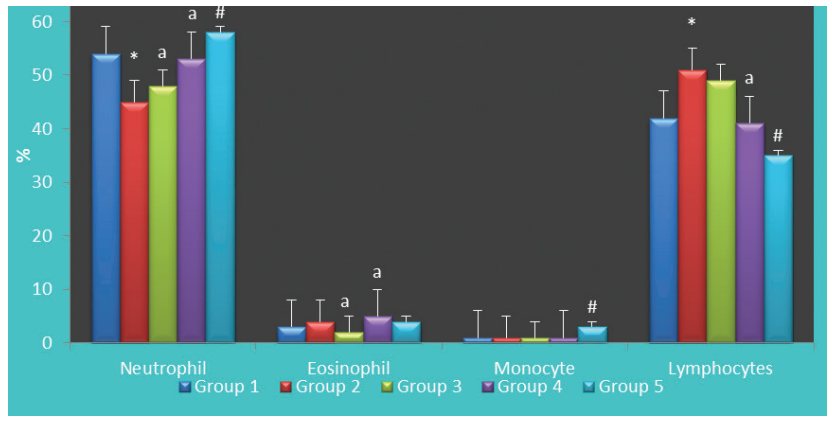

Figure 3: Effect of vildagliptin and insulin on haematological parameters in diabetic rats. ${ }^{*} \mathrm{P}<0.001$, statistically significant as compared with control rats: aP<0.05, statistically significant as compared with diabetic rats and \#P<0.01, statistically significant as compared with normal.

when compared to mono therapies with vildagliptin in which the infection has been lowered to some extent when compared to insulin mono therapy. The level of eosinophils has been elevated in Insulin monotherapy as well as in combinatorial therapy due to elevated infections when compared to vildagliptin monotherapy. The level of monocytes has been elevated in the combinatorial therapy due to elevated infections when compared to monotherapies. The immunity i.e the level of lymphocytes has been significantly reduced in the combinatorial therapy when compared to the mono therapies with vildagliptin and insulin (Figure 2).

The level of Hb, PCV [Packed Cell Volume], RBC cells and Platelet count has been lowered in the diabetic rats but in the vildagliptin treated rats it has been slightly improved. In insulin treated rats it has been further improved but in the combinatorial therapy it has been lowered drastically when compared to the monotherapy showing that the combinatorial therapy makes the rats anaemic (Figure 3). 


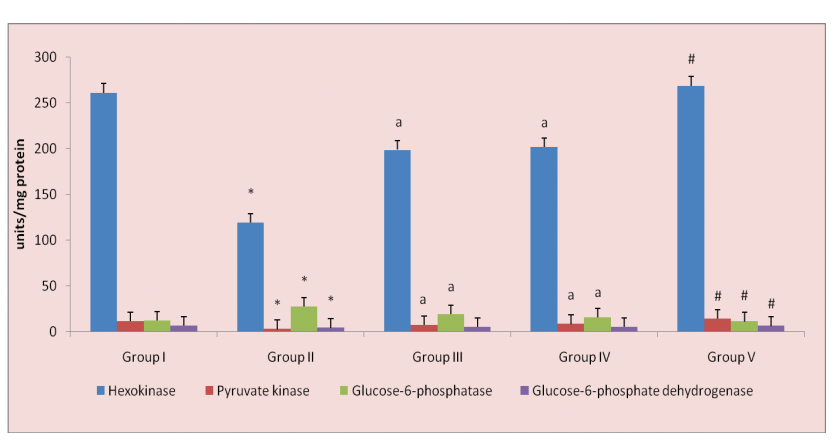

Figure 4: Effect of vildagliptin insulin on glucose metabolising enzyme activities in diabetic rats. Results are expressed as mean $\pm S . E . M, n=6 .{ }^{*} P<0.001$, statistically significant as compared with control rats: $\mathrm{aP}<0.01$, statistically significant as compared with diabetic rats; $b P<0.05$, statistically significant as compared with diabetic rats and $\# \mathrm{P}<0.01$, statistically significant as compared with normal.

\section{Effect of insulin and vildalgliptin on glucose metabolizing enzymes}

With regard to the glucose metabolizing enzymes their levels have been far deviated from the normal levels so that the glucose metabolism was severely affected showing that there is significant hepatic tissue damage in the combinatorial therapy when compared to the monotherapy as the glucose metabolism is very much affected (Figure 4).

\section{DISCUSSION}

The reports of suspected adverse drug reactions (ADRs) can yield important information regarding the safety of drugs. Hypoglycaemia is mostly produced by the insulin therapy and prevents the therapy from bringing back the glycemic control. The glycemic control will be achieved in some cases but the rate of hypoglycaemia produced will be higher. If the vildagliptin has been added to the insulin therapy it will produce hypoglycaemia to a greater extent through decrease in glucagon secretion ${ }^{10}$ through GLP-1 induced pathway which in turn produces severe hepatic and other tissue damage.

The safety of vildagliptin and other oral antidiabetic agents were assessed by testing certain parameters in the laboratory especially the parameters for finding out the hepatic safety have been tested ${ }^{11}$.The difference in the values between normal and drug treated subjects is very less but it produces severe hypoglycaemia during the glucose control in the diabetes ${ }^{12}$. The diabetes mellitus induced by alloxan produces severe anaemia which is of the hypochromic microcytic type which produces a fall in PCV [Packed Cell Volume], RBC, Hb, MCV [Mean Corpuscular Volume] in diabetic rats. It is caused by the effect of alloxan on haemopoietic cells by the suppression of haemopoietic processes due to insulin deficiency which produces destruction of beta cells of the islets of langerhans of the pancreas. ${ }^{13}$

The level of RBC has been lowered in the diabetic patients but in the vildagliptin treated patients it has been slightly improved. In insulin treated patients it has been increased less significantly but in the combinatorial therapy it has been lowered drastically when compared to the monotherapy showing that the combinatorial therapy makes the patient anaemic. The anaemia associated with the diabetes has been produced by the glycosylation of $\mathrm{RBC}$ membrane proteins. The lipid peroxides have been oxidised in diabetes mellitus producing haemolysis of the RBC. The glycosylation of membrane proteins of the RBC has been associated with hyperglycemia. ${ }^{11}$ The peroxidation of membrane lipids produces increase in the membrane rigidity, decrease in cellular deformability and increase in the fluidity of lipids. ${ }^{14}$

According to Isaac the transport of oxygen and absorbed nutrients is carried out by packed cell volume. Better transport can be accomplished by increase in packed cell volume which in turn produces primary and secondary polycythemia. But administration of alloxan may lead to abnormality in haemoglobin synthesis and failure of regulation of osmolarity. ${ }^{15}$ The haematological parameters and the immune system were altered in the diabetes mellitus which has been revealed by Mansi and Lahham. ${ }^{16}$ The importance of activated platelet in atherosclerosis has been investigated by the antiplatelet agents. The thiazolidinediones have been found to reduce platelet dependent thrombus formation by restoring glycemic control in a study conducted in diabetic patients without cardiovascular diseases.

The animals with low white blood cells are prone to high risk of infection whereas the animals with high number of white blood cells are capable of producing more number of antibodies and provide high degree of resistance to diseases in all sorts of environmental conditions. In Diabetes Mellitus the Polymorpho Mononuclear leukocytes were activated by oxidative stress, advanced glycation end products, Angiotensin $\mathrm{II}^{17}$ and cytokines. The combinatorial therapy group showed loss of immunity by altering significantly the haematological parameters.

The enzymes involved in the catabolism of glucose such as hexokinase and pyruvate kinase has been considerably decreased in the diabetes mellitus. Alterations in G6PDH activity can significantly alter oxidative stress-induced cell death. Insulin is reported to stimulate oxidation of glucose by increasing the activation of G6PDH. ${ }^{18}$ The regulatory enzymes in gluconeogenesis such as Glucose-6-Phosphatase and Fructose1, 6 Diphosphatase have been significantly elevated in 
diabetic control animals ${ }^{19}$ especially in alloxan induced diabetes due to insulin insufficiency. The level of hexokinase has been significantly increased in the combinatorial therapy showing that there is a production of hypoglycaemia which in turn leads to hepatic tissue damage. ${ }^{20}$ The level of glucose-6-phosphatase has been reduced significantly when compared to monotherapies showing that the metabolism of carbohydrate has been slowed down and the ATP production has been reduced due to hepatic tissue damage. As the level of glucose6-phosphatase has been lowered in the combinatorial therapy when compared to the monotherapies the rate of carbohydrate metabolism is lowered and the glucose phosphorylation may be blocked.

There is a decrease in the formation of Glucose-6-phosphate which is very important for the production of NADPH and Acetyl coA for lipid synthesis. There is a marked fall in the level of glucose 6-phosphate dehydrogenase which in turn decreases the formation of ${ }^{14} \mathrm{CO}_{2}$ from glucose, which in turn leading to a decrease in the contribution of the Pentose Phosphate pathway. ${ }^{21}$ The energy in the form of ATP and NADH is produced by Glucose-6-phosphate (G6P) in glycolysis and also it is used to store energy in the form of glycogen and also it is used by the pentose phosphate pathway. Significant decreases in G6PD [glucose-6-phosphate dehydrogenase] activity due to hyperglycemia or diabetes in all the cells and tissues of the body may lead to severe anaemia. ${ }^{21}$ Thus the level of Glucose-6-phosphate dehydrogenase has been reduced in the combinatorial therapy due to tissue damage which in turn leading to poor conformations of the erythrocytes leading to anaemia and reduced antioxidant activity of the enzyme. Here in our experiment also the adverse effects of hypoglycaemia due to the administration of combinatorial therapy on glucose metabolizing enzymes can be evident. The challenge of treating diabetes in this section of population is to avoid hypoglycemia. The elderly are frequently on polypharmacy, which opens the door for potential drug interactions. ${ }^{22}$

In our previous study we have reported the adverse effect of vildalgliptin and insulin combinatorial therapy in the experimentally induced Type 2 diabetic rat model and also in humans ${ }^{23,24}$ which supports the results of the present study.

\section{CONCLUSION}

The adverse effects of vildalgliptin and insulin combined therapy to diabetic condition includes the damage to the hepatic tissues leading to glucose metabolizing enzymes misregulation and also producing neutrophil infiltra- tion, reduction in the level of immunity and increase in the infections by the alterations in the haematological parameters.

\section{Ethical approval}

All applicable international, national, and/or institutional guidelines for the care and use of animals were followed.

\section{ACKNOWLEDGEMENT}

The authors thank Dr. Shankar for providing the interpretation for histological slide.

\section{CONFLICT OF INTEREST}

The author declare that there is no conflict of interest.

\section{ABBREVIATIONS USED}

RBC: Red blood cell; Hb: Hemoglobin; ATP: Adenosine TriPhosphate; NADH: Nicotinamide Adenine Dinucleotide Hydrate; NADPH: Nicotinamide adenine dinucleotide phosphate reduced.

\section{REFERENCES}

1. Bolli GB, Songini M, Trovati M, Del Prato S, Ghirlanda G, Cordera R, Trevisan R, Riccardi G, Noacco C. Lower fasting blood glucose, glucose variability and nocturnal hypoglycaemia with glargine vs NPH basal insulin in subjects with Type 1 diabetes. Nutr Metab Cardiovasc Dis. 2009;19(8):571-9. https://doi. org/10.1016/j.numecd.2008.05.003 PMid:18676131.

2. Rambhade SK, Singh S, Goswami RB, Rambhade A. Occurrence, Complications, and Interventions of Diabetes: A New Understanding of an Old Problem. Syst Rev Pharm. 2011;2(1):8-18. https://doi.org/10.4103/09758453.83433.

3. Vishal S, Bajwa SJS, Sehgal R, Consalvo JA. Management of diabetes in the elderly with canagliflozin: A newer hypoglycemic drug on the horizon. 2014;5(4):227-31.

4. Nathan DM, Buse JB, Davidson MB. Management of hyper-glycaemia in type 2 diabetes mellitus: a consensus algorithm for the initiation and adjustment of therapy: Update regarding the thiazolidin-ediones. Diabetologia. 2008;51:811. https://doi.org/10.1007/s00125-007-0873-z https://doi.org/10.1007/ s00125-007-0917-4 PMid:18026926.

5. Langley AK, Suffoletta TJ, Jennings HR. Dipeptidyl peptidase IV inhibitors and the incretin system in type 2 diabetes mellitus. Pharmacotherapy. 2007;27(8):1163-80. https://doi.org/10.1592/phco.27.8.1163 PMid:17655515.

6. Ahren B, Pacini G, Foley JE. Improved meal-related beta-cell function and insulin sensitivity by the dipeptidyl peptidase-IV inhibitor vildagliptin in metformin-treated patients with type 2 diabetes over 1 year. Diabetes Care. 2005;28(8):1936-40. https://doi.org/10.2337/diacare.28.8.1936 PMid:16043735.

7. Shekha MS. The effects of rhubarb root and antihyperlipidemic drug on some physiological parameters in male rats. J Dohuk Univ. 2008;11:136-43.

8. Burkey BF, Li X, Bolognese L, Balkan B, Mone M, Russell M., et al. Acute and chronic effects of the incretin enhancer vildagliptin in insulin-resistant rats. J Pharmacol Exp Ther. 2005;315(2):688-95. https://doi.org/10.1124/ jpet.105.087064 PMid:16027230.

9. Rodriguez R, Viscarra JA, Minas JN, Nakano D, Nishiyama A, Ortiz RM., et al. Angiotensin receptor blockade increases pancreatic insulin secretion and decreases glucose intolerance during glucose supplementation in a model 
of metabolic syndrome. Endocrinology. 2012; 153(4):1684-95. https://doi. org/10.1210/en.2011-1885 PMid:22355070 PMCid:PMC3320242.

10. Lee CM, Huxley RR, Lam TH, Martiniuk AL, Ueshema H, Pan WH, Welborn T, Woodward M. et a/ Prevalence of diabetes mellitus and population attributable fractions for coronary heart disease and stroke mortality in the WHO SouthEast Asia and Western Pacific regions. Asia Pac J Clin Nutr. 2007;16(1):187-92. PMid:17215197.

11. Nikolaidis LA, Mankad S, Sokos GG. Effects of glucagon-like peptide-1 in patients with acute myocardial infarction and left ventricular dysfunction after successful reperfusion. Circulation. 2004;109(8):962-5. https://doi. org/10.1161/01.CIR.0000120505.91348.58 PMid:14981009.

12. Keating GM. Vildagliptin: a review of its use in type 2 diabetes mellitus. Drugs. 2010;70(16):2089-112 https://doi.org/10.2165/11206370-00000000000000 PMid:20964454.

13. Patel A, MacMahon S, Chalmers J, Neal B, Billot L, Wood-ward M, Marre M, Cooper M, Glasziou P, Grobbee D, Hame Kothny W et al. An assessment of adverse effects of vildagliptin versus comparators on the liver, the pancreas, the immune system, the skin and in patients with impaired renal function from a large pooled database of Phase II and III clinical trials. Diabetes Obes Metab. 2010;12:495-509. https://doi.org/10.1111/j.1463-1326.2010.01214.x PMid:20518805.

14. Gerstein HC, Miller ME, Byington RP, Goff DC, Bigger JT, Buse JB, Cushman WC, Genuth S, Ismail-Beigi F, Grimm RH, Probstfield JL, Simons-Morton DG, Friedewald WT. et al Effects of intensive glucose lowering in type 2 diabetes. N Engl J Med. 2008;358:2545-59. https://doi.org/10.1056/NEJMoa0802743 PMid:18539917 PMCid:PMC4551392.

15. Isaac LJ, Abah G, Akpan B, Ekaette IU. Haematological properties of different breeds and sexes of rabbits. Proceedings of the 18th Annual Conference of Animal Science Association of Nigeria. 2013;24-7.

16. Mansi K, Lahham J. Effects of Artemisia sieberi Besser (a. herba-alba) on heart rate and some hematological values in normal and alloxan-induced diabetic rats. J Basic Appl Sci. 2008;4:57-62.

\section{Pictorial Abstract}

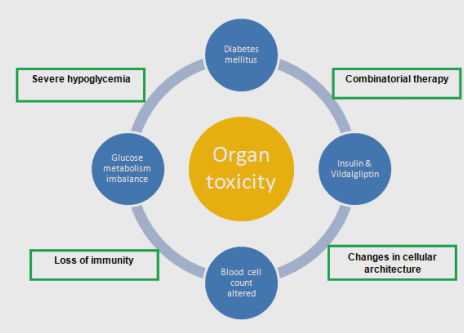

\section{About Authors}

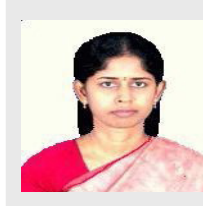

Dr. Mallika Jainu: Is working as a Assistant Professor in the Department of Biomedical Engineering, Sri Siva Subramaniya Nadar College of Engineering, Chennai, India. She has published more than 100 research article in international journals and international conference. She has also published many chapters in academic books in aspect of Biochemsitry.

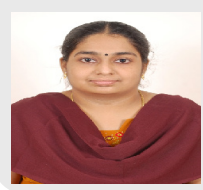

E.Priya: She completed M.Sc., M.Phil degree from University of Madras, Currently she is doing Ph.D in the Research \& Development Centre, Bharathiar University, Coimbatore. She has published more than 10 research article in International journals. This research work has been shortlisted under DST WOS-B scheme.
17. Lee P, Peng H, Gelbart T, Beutler E. The IL-6- and lipopolysaccharide induced transcription of hepcidin in HFE-, transferrin receptor 2-, and beta 2-microglobulin-deficient hepatocytes. Proc Natl Acad Sci USA. 2004;101(25):9263-5. https://doi.org/10.1073/pnas.0403108101 PMid:15192150 PMCid:PMC438964.

18. Grover JK, Vats V, Rathi SS. Anti-hyperglycaemic effect of Eugenia jambolana and Tinospora cordifolia in experimental diabetes and their effects on key metabolic enzymes involved in carbohydrate metabolism. J Ethnopharmacol. 2000;73(3):461-70. https://doi.org/10.1016/S0378-8741(00)00319-6.

19. Boyle PJ, Nagy RJ, O'Connor AM, Kempers SF, Yeo RA, Qualls C. Adaptation in brain glucose uptake following recurrent hypoglycemia. Proc Natl Acad Sci U.S.A. 1994;91(20):9352-6. https://doi.org/10.1073/pnas.91.20.9352 PMid:7937768 PMCid:PMC44810.

20. Kolanjiappan K, Manoharan S, Kayalvizhi M. Measurement of erythrocyte lipids, lipid peroxidation, antioxidants and osmotic fragility in cervical cancer patients. Clin Chim Acta. 2002;326:143-9. https://doi.org/10.1016/S00098981(02)00300-5.

21. Zhang Z, Liew CW, Handy DE, Zhang Y, Leopold JA, Hu J, Guo L, Kulkarni RN, Loscalzo J, Stanton RC. High glucose inhibits glucose-6-phosphate dehydrogenase, leading to increased oxidative stress and beta-cell apoptosis. Faseb J. 2010;24(5):1497-1505. https://doi.org/10.1096/fj.09136572 PMid:20032314 PMCid:PMC2879949.

22. Karuna R, Ramesh B, Sreenivasa R, Singareddy, Saralakumari D, Antihyperglycemic activity of Catharanthus roseus leaf powder in streptozotocin-induced diabetic rats. Pharmacog Res. 2010;2(3):195-201. https://doi.org/10.4103/0974-8490.65523 PMid:21808566 PMCid:PMC3141314.

23. Priya E, Mallika J. Study of adverse effects of vildagliptin and insulin treatment in diabetes mellitus patients. Research J Rec Sci 2014;3:1-8.

24. Priya E, Mallika J. Adverse effects of combinatorial therapy of vildagliptin and insulin on cardiac tissues in diabetic rats. Ind J Sci Tech. 2016;9(3):1-5. https://doi.org/10.17485/ijst/2016/v9i3/84256.

\section{SUMMARY}

- Current gold standard therapeutic strategies for T2DM target insulin resistance or a cell dysfunction as their core mechanisms of action. Our research topic is about the ADR produced by combinatorial therapy of dipeptidyl peptidase-4 (DPP-4) inhibitors and insulin which are the most recent addition to the treatment options available in clinical practice for the treatment of T2DM.So there is a need for getting rid of their adverse effects like multiorgan toxicity and ACE [Angiotensin converting enzyme inhibitor] inhibitor associated angioedema, hypoglycaemia etc., which have been already proved and new drugs have to be developed which are devoid of all these adverse effects.

Cite this article: Ebenesan P, Jainu M. Vildagliptin and Insulin Combinatorial Therapy Drug Safety Monitoring in Diabetic Rats. Indian J of Pharmaceutical Education and Research. 2017;51(1):150-55. 